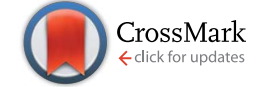

Cite this: RSC Adv., 2017, 7, 8944
Received 27th December 2016 Accepted 19th January 2017

DOI: 10.1039/c6ra28747f

www.rsc.org/advances

\section{Catalytic hydrothermal liquefaction of Euglena sp. microalgae over zeolite catalysts for the production of bio-oil $\uparrow$}

\author{
Bo Zhang, ${ }^{\text {ab }}$ Qisong Lin, ${ }^{\text {a }}$ Qinhui Zhang, ${ }^{\text {bc }}$ Kejing Wu, ${ }^{a}$ Weihua $\mathrm{Pu}^{a}{ }^{a}$ Mingde Yang $^{a}$ \\ and Yulong $\mathrm{Wu}^{\star a d}$
}

In this paper, Euglena sp. microalgae with low lipid and high ash contents were successfully converted into bio-oil with/without catalysts through hydrothermal liquefaction $(\mathrm{HTL})$ at $280{ }^{\circ} \mathrm{C}$ and a reaction time of 30 min. The introduction of acidic microporous zeolite catalysts (HZSM-22, HZSM-5, H beta, MCM-22, and SAPO-11) with high hydrothermal stability further improved the bio-oil quality in situ. Various methods, including elemental analysis, high heat value (HHV), and gas chromatography (GC)-mass spectrometry (MS), were used to analyze the physicochemical properties of the obtained bio-oil. Results indicated that catalyst addition could enhance $\mathrm{C}$ and $\mathrm{H}$ contents, reduce $\mathrm{O}$ and $\mathrm{N}$ contents, and also improve HHV (the maximum value of $37.08 \mathrm{MJ} \mathrm{kg}^{-1}$ was obtained for the $\mathrm{H}$ beta catalyst). GC-MS revealed that the bio-oil obtained by direct $\mathrm{HTL}$ contained relatively high amounts of $\mathrm{N}$-containing compounds (30.87\%) and acid compounds (16.44\%). Meanwhile, the catalysts introduced in situ not only lowered the contents of nitrogen and acids to some extent, but also simultaneously increased the hydrocarbon content. This result was most pronounced over the $\mathrm{H}$ beta catalyst, which reduced the nitrogen content to $16.68 \%$ and decreased the acid content to $9.50 \%$. The hydrocarbon content increased to $43.43 \%$. Ultimately, a reasonable reaction network for Euglena sp. HTL was proposed and provides a basis for the process's further industrialization.

\section{Introduction}

The global economy is rapidly developing, the global population is growing, traditional fossil fuels are being aggressively depleted, and environmental pollution and climate change are worsening. ${ }^{1}$ Hence, a new form of energy, which could supplement or replace traditional fossil fuels, must be urgently developed. Among the substitutes, biofuels obtained from biomass, especially from microalgae, have attracted wide attention in recent decades. This interest was motivated by the microalgae's high photosynthetic efficiency, high area-specific yield relative to terrestrial biomass, noncompetition with cultivated land, and capacity to use exhaust gas and wastewater as nutrients. ${ }^{2}$ In obtaining biofuels, hydrothermal liquefaction (HTL) was identified as an ideally effective conversion method

anstitute of Nuclear and New Energy Technology, Tsinghua University, Beijing 100084, PR China. E-mail: wylong@tsinghua.edu.cn; Fax: +86 10 69771464; Tel: +86 10 89796163

${ }^{b}$ College of Chemical Engineering, China University of Petroleum, Qingdao 266580, PR China

${ }^{c}$ College of Chemistry and Chemical Engineering, Fujian Normal University, Fuzhou 350117, PR China

${ }^{d}$ Beijing Engineering Research Center for Biofuels, Beijing 100084, PR China

$\uparrow$ Electronic supplementary information (ESI) available. See DOI: $10.1039 / \mathrm{c} 6 \mathrm{ra} 28747 \mathrm{f}$ for microalgae with high moisture. Particularly, HTL not only obtains a high liquid conversion rate but also does not require any drying pretreatment.

Compared with conventional fossil energy, the bio-oil obtained from HTL contains high oxygen, nitrogen, and sulfur contents, which are strongly affected by feedstock constituents. ${ }^{3}$ Therefore, contraposing different feedstocks is necessary in choosing or designing different catalysts to improve the bio-oil quality. At present, two main strategies exist to enhance bio-oil quality. The first strategy involves (1) introduction of catalysts to microalgae HTL to directly acquire high-quality bio-oil (named as "one-pot method"). The second strategy involves (2) initial bio-oil acquisition by HTL followed by the use of catalysts to upgrade the bio-oil quality (designated as "two-step method"). ${ }^{4}$ The one-pot method holds remarkable advantages, such as simple operational procedures and low energy consumption, over the two-step method. ${ }^{5}$ Currently, the homogeneous catalysts, such as alkali $\left(\mathrm{Na}_{2} \mathrm{CO}_{3}\right.$ and $\left.\mathrm{KOH}\right)$ and organic acids (formic acid and acetic acid), have been used in microalgae HTL. ${ }^{6}$ Using different catalysts could help extract bio-oil with different properties. For instance, alkali could effectively promote liquefaction, increase bio-oil yield, and suppress char formation, ${ }^{7}$ whereas organic acids could improve bio-oil flow properties and decrease the boiling point. Heterogeneous catalysts introduced in situ for microalgae HTL are more desirable than 
homogeneous catalysts because heterogeneous catalysts are easier to separate from reaction products. Duan and Savage ${ }^{\mathbf{8}}$ studied the effect of several heterogeneous catalysts $(\mathrm{Pd} / \mathrm{C}, \mathrm{Pt} / \mathrm{C}$, $\mathrm{Ru} / \mathrm{C}, \mathrm{Ni} / \mathrm{SiO}_{2}-\mathrm{Al}_{2} \mathrm{O}_{3}$, and $\mathrm{CoMo} / \gamma-\mathrm{Al}_{2} \mathrm{O}_{3}$ (sulfided)) on the catalytic HTL of microalga Nannochloropsis sp. The study showed that when $\mathrm{Pd} / \mathrm{C}$ catalyst was used without hydrogen, the obtained bio-oil yield increased to $57 \%$ relative to that $(35 \%)$ of direct HTL without catalysts. The bio-oil obtained over these catalysts also exhibited a relatively low viscosity and light color compared with the noncatalyzed products. Another transition metal oxide (NiO) catalyst was also introduced in the HTL of Spirulina platensis microalgae. ${ }^{9}$ Although the $\mathrm{NiO}$ catalyst did not increase the bio-oil yield, the catalyst's addition resulted in the increased selectivity for monoaromatic compounds. Biller et $a l .{ }^{10}$ explored the performance of three catalysts $\left(\mathrm{Pt} / \mathrm{Al}_{2} \mathrm{O}_{3}, \mathrm{Ni} /\right.$ $\mathrm{Al}_{2} \mathrm{O}_{3}$, and $\mathrm{Co} / \mathrm{Mo} / \mathrm{Al}_{2} \mathrm{O}_{3}$ ) in the catalytic $\mathrm{HTL}$ of the two microalgae Chlorella vulgaris and Nannochloropsis occulta. The study showed that the bio-oil yields increased slightly over these heterogeneous catalysts. Meanwhile, the high heat value (HHV) and the level of deoxygenation increased up to $10 \%$. Chen et al. ${ }^{11}$ investigated in detail the influence of acid/base catalysts on the catalytic HTL of D. tertiolecta. The acid/base property of the catalyst played different crucial roles in the catalytic HTL process, especially for the KtB base catalyst, which could obtain the maximum conversion rate $(94.84 \%)$ and bio-oil yield (49.09\%).

Despite the fact that the different catalyst types used, such as zeolite catalysts, exhibited excellent catalytic effects during microalgal HTL, no systematic report other than that of Xu et al. ${ }^{12}$ exists. In the study, the scholars investigated the effect of HZSM-5 and Ce/HZSM-5 catalysts on C. pyrenoidosa HTL. As a common catalyst, zeolite contains various pore structures, numerous active sites, as well as large surface areas, usually acid sites, which facilitate the catalysis of cracking reaction. Furthermore, the strength and concentration of the acid sites could be tailored to specific applications. ${ }^{13}$ Nonetheless, the zeolite catalysts with cracking characteristics are mostly used in the bio-oil upgrading process. Widayatno et al. ${ }^{\mathbf{1 4}}$ investigated high-silica zeolite (HSZ-385, 890, 960, and 990) to selectively catalyze bio-oil conversion. The study showed that all of the zeolite materials possess a high deoxygenation ability for the bio-oil by $\mathrm{H}_{2} \mathrm{O}$ removal from acid sites. The beta-type zeolite of HSZ-960 showed a high selectivity for hydrocarbons. Duan et $a{ }^{15}$ investigated the nine-type zeolite with different $\mathrm{Si} / \mathrm{Al}$ ratios for the catalytic hydrothermal upgrading of pretreated algal bio-oil with $\mathrm{H}_{2}$ addition. All of the zeolite promoted the deoxygenation and denitrification reaction of the pretreated bio-oil because of the presence of acid sites. In brief, modest research is available on the effects of different zeolites on the catalytic HTL of microalgae, especially the studies that systematically compare and analyze results. Hence, drawing a clear conclusion on the basis of the works published by different groups is difficult.

In this paper, the microalga Euglena sp., which holds the advantage of having both animal and plant characteristics and being highly unmutated, was first used as HTL feedstock. Five different zeolite catalysts (HZSM-22, HZSM-5, H beta, MCM-22, and SAPO-11) were also introduced in the HTL of Euglena sp. in a batch-type reactor. The physicochemical properties of the obtained bio-oil with/without catalysts were studied by elemental analysis (EA), HHV, and gas chromatography (GC)mass spectrometry (MS) in detail. Meanwhile, a reasonable reaction network for Euglena sp. HTL was also proposed.

\section{Experimental}

\subsection{Materials}

The feedstock of Euglena sp. microalgae was purchased from Xi'an Victory Biochemical Co. (Xi'an, China). The feedstock was firstly mashed in agate mortar, followed by sieved at 200 mesh sieve, then dried at $105{ }^{\circ} \mathrm{C}$ for $12 \mathrm{~h}$ prior to use. The analysis of Euglena sp. feedstock was shown in Table 1 . The five zeolite catalysts, including HZSM-22 $\left(\mathrm{SiO}_{2} / \mathrm{Al}_{2} \mathrm{O}_{3}\right.$ molar ratio of 90), HZSM-5 $\left(\mathrm{SiO}_{2} / \mathrm{Al}_{2} \mathrm{O}_{3}\right.$ molar ratio of 60$), \mathrm{H}$ beta $\left(\mathrm{SiO}_{2} / \mathrm{Al}_{2} \mathrm{O}_{3}\right.$ molar ratio of 30), MCM-22 $\left(\mathrm{SiO}_{2} / \mathrm{Al}_{2} \mathrm{O}_{3}\right.$ molar ratio of 50), SAPO-11 $\left(\mathrm{SiO}_{2} / \mathrm{P}_{2} \mathrm{O}_{5} / \mathrm{Al}_{2} \mathrm{O}_{3}=0.7: 1: 1\right)$ were provided by Shanghai Novel chemical technology co., LTD. All other chemicals used were of analytical reagent grade without any purification. The water used was deionized water.

\subsection{Experimental procedures}

The experiments have been carried out in a non-stirred batchtype stainless steel reactor with a volume capacity of $50 \mathrm{~mL}$ and heated by an external electrical furnace, which is designed to a maximum temperature of $500{ }^{\circ} \mathrm{C}$ and pressure of $35 \mathrm{MPa}$. The Euglena sp. processed by HTL were carried out based on $3 \mathrm{~g}$ dry microalgae with $30 \mathrm{~mL}$ deionized water with/without 10 $\mathrm{wt} \%$ catalysts (based on dry weight of microalgae). And

Table 1 Analysis results of Euglena feedstock ${ }^{a}$

\begin{tabular}{ll}
\hline Analyses & Euglen \\
\hline Proximate analysis (wt\%) & \\
Moisture $W_{\mathrm{ar}}$ & 4.1 \\
Volatiles $V_{\mathrm{ar}}$ & 55.75 \\
Ash $A_{\mathrm{ar}}$ & 29.42 \\
Fixed carbon $C_{\mathrm{Far}}$ & 10.73
\end{tabular}

Biochemical composition analysis (wt\%) $)^{\text {ar }}$

Carbohydrates $\quad 49.5$

Protein 30.4

Lipids $\quad 11.8$

Chlorophyll $\quad 0.34$

$\begin{array}{ll}\text { Other }^{b} & 7.96\end{array}$

Elemental analysis (wt\% daf $)^{c}$

C 32.76

$\mathrm{H} \quad 5.14$

$\mathrm{N} \quad 3.81$

$\mathrm{O}^{b} \quad 28.87$

$\mathrm{H} / \mathrm{C}$ (molar ratio) $\quad 1.88$

$\mathrm{O} / \mathrm{C}$ (molar ratio) $\quad 0.66$

$\mathrm{HHV}\left(\mathrm{MJ} \mathrm{kg}^{-1}\right) \quad 13.29$

${ }^{a}$ ar $=$ as received. daf $=$ dry ash free. ${ }^{b}$ Determined by difference.

${ }^{c}$ Average of duplicates. 
reactions were carried out at the temperatures of $280{ }^{\circ} \mathrm{C}$ with $10{ }^{\circ} \mathrm{C} \mathrm{min}^{-1}$ heating rate from room temperature and a constant retention time (30 $\mathrm{min}$ ), this condition was based on the previously optimized results of process parameters from Euglena sp. HTL. The mixture product of oil-water-solid were obtained after HTL, and then decanted into Buchner funnel. The solid residue was washed by using dichloromethane (DCM) solvent three times ( $30 \mathrm{~mL}$ each time) in the process of the suction filter until the eluent presented colorless, subsequently, the solid residue was transferred into drying oven at $105{ }^{\circ} \mathrm{C}$ for $24 \mathrm{~h}$, and weighted to figure out the conversion ratio. Then, the resulting mixture, except the solid residue, was extracted three times using DCM (30 mL each time) and separated in a separating funnel, followed by DCM solvent evaporation by the rotary evaporator to obtain bio-oil and calculate the yield. During the experiment, the gases were not collected and vented in a fume hood when the reactor was opened after the experiment. The HTL experiment without catalyst was used as comparison, which was named as blank in this paper. The compendious process schematic was depicted in Fig. 1.

The conversion ratio and the yield of the bio-oil were calculated on the basis of the formulas below, respectively, in which, $W$ was defined as the mass $(\mathrm{g})$.

$$
\begin{gathered}
C_{\text {Euglena sp. }}\left(\mathrm{wt}^{\%} \%\right)=\left[1-\left(W_{\text {solid residue }} / W_{\text {feedstock }}\right)\right] \times 100 \% \\
Y_{\text {bio-oil }}(\mathrm{db})(\mathrm{wt} \%)=\left(W_{\text {bio-oil }} / W_{\text {feedstock }}\right) \times 100 \%
\end{gathered}
$$

where db refers to dry basis.

\subsection{Analytical test instruments}

$\mathrm{N}_{2}$ adsorption-desorption isotherms were measured on a Micromeritics ASAP2460 instrument at $77 \mathrm{~K}$. The surface area information of catalysts was calculated using the BrunauerEmmett-Teller (BET) method. Temperature-programmed desorption of ammonia $\left(\mathrm{NH}_{3}\right.$-TPD) measurements were carried on a TP-5076 multifunctional automatic adsorption instrument (Xianquan Industry and Trade Development Co., Tianjin, China). Typically, $0.1 \mathrm{~g}$ of catalyst was used, the catalyst was pretreated at $450{ }^{\circ} \mathrm{C}$ for $1 \mathrm{~h}$ under a flow of $\mathrm{He}(30 \mathrm{~mL}$ $\left.\min ^{-1}\right)$, then adsorbed $\mathrm{NH}_{3}\left(15 \mathrm{~mL} \min ^{-1}\right)$ at $100{ }^{\circ} \mathrm{C}$ for $30 \mathrm{~min}$, and purged with $\mathrm{He}$ until the physically adsorbed $\mathrm{NH}_{3}$ was removed. Later, the catalyst was heated in a flow of $\mathrm{He}(30 \mathrm{~mL}$ $\min ^{-1}$ ) from 100 to $900{ }^{\circ} \mathrm{C}$ with a ramp of $5{ }^{\circ} \mathrm{C} \mathrm{min}^{-1}$. The signal values of $\mathrm{NH}_{3}$-TPD were recorded by an online thermal conducted detector (TCD). The TGA experiments were carried out in a TA Instruments SDT Q600 thermogravimetric analyzer. $10 \mathrm{mg}$

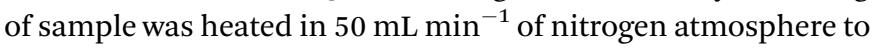
$900{ }^{\circ} \mathrm{C}$ at $10{ }^{\circ} \mathrm{C} \mathrm{min}^{-1}$.

The gas chromatography-mass spectrometry (GC-MS) was analyzed on a Trace DSQ GC-MS system with an AB-5MS capillary column ( $30 \mathrm{~m} \times 0.25 \mathrm{~mm}$ id, $0.25 \mu \mathrm{m}$ film thickness), the high-purity helium was used as carrier gas with a flow rate of 1 $\mathrm{mL} \mathrm{min}^{-1}$. The column temperature was programmed from 333 to $573 \mathrm{~K}$ at a rate of $10 \mathrm{~K} \mathrm{~min}^{-1}$ after an initial 2 min isothermal period, and then it was kept at the final temperature for $10 \mathrm{~min}$. The inlet temperature was set to $573 \mathrm{~K}$, and the split ratio was $1: 50$. The mass spectrometer was set to an ionizing voltage of $70 \mathrm{eV}$ with a mass range from 35 to $650 \mathrm{amu}$. Compounds were identified according to the NIST library.

The elemental composition was analyzed using VARIO EL III elemental analyzer to determine the $\mathrm{C}, \mathrm{H}, \mathrm{N}$ content of the samples (including Euglena sp. feedstock and bio-oil) and $\mathrm{O}$ determined by difference. For each sample, elemental analysis was carried out in duplicate. Only average values were reported. $\mathrm{HHV}$ was calculated via Dulong formula ${ }^{\mathbf{1 6}}$ which is valuable for comparison across similar bio-oils.

$$
\operatorname{HHV}\left(\mathrm{MJ} \mathrm{kg}^{-1}\right)=0.3383 \times C+1.442 \times(H-O / 8)
$$

where $C, H$, and $O$ meant the weight percentage of carbon, hydrogen, and oxygen, respectively.

The energy recovery ratio (ERR) proposed by Minowa et al. ${ }^{17}$ and Yokoyama et al. ${ }^{18}$ was aimed to study the energy of the resultant products relative to the energy input of the material. The energy recovery of feedstock to oil was calculated based on the following equation

$$
\begin{aligned}
\operatorname{ERR}(\%) & =\left(E_{\mathrm{p}} / E_{\text {feedstock }}\right) \times 100 \% \\
& =\left(Y_{\text {bio-oil }} \times \mathrm{HHV} V_{\text {bio-oil }}\right) / \mathrm{HHV}_{\text {feedstock }} \times 100 \%
\end{aligned}
$$

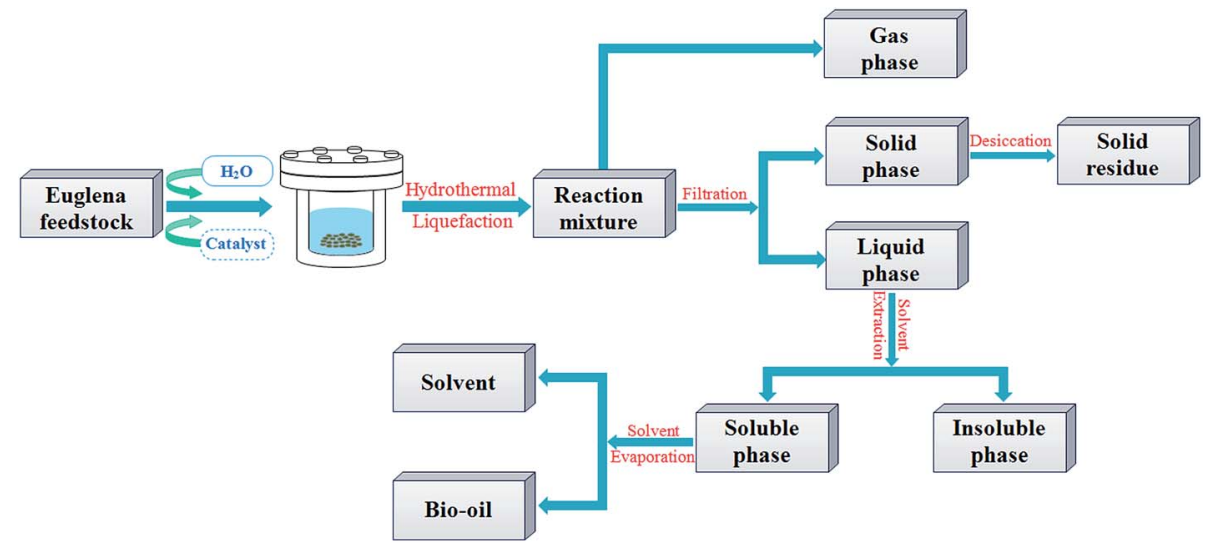

Fig. 1 The compendious process schematic for Euglena HTL with/without catalysts. 
where, $E_{\mathrm{p}}$ and $E_{\text {feedstock }}$ were the energy content of the products (bio-oil) and the Euglena sp., respectively. The bio-oil yields were expressed on dry basis and high heating values on $\mathrm{MJ} \mathrm{kg}^{-1}$.

\section{Results and discussion}

\subsection{Catalytic HTL of Euglena sp.}

The proximate analysis, biochemical composition analysis, and elemental compositions of Euglena sp. feedstock are presented in Table 1. The main biochemical compositions were carbohydrates (49.5\%), protein (30.4\%), and lipids (11.8\%). Meanwhile, the ash content was substantially high and reached $29.42 \%$. These results illustrate that the Euglena sp. feedstock belonged to microalgae with low lipid and high ash contents. EA revealed that the contents of $\mathrm{C}, \mathrm{H}, \mathrm{N}$, and $\mathrm{O}$ of the Euglena sp. feedstock were $32.76 \%, 5.14 \%, 3.81 \%$, and $28.87 \%$, respectively. The HHV was 13.29 $\mathrm{MJ} \mathrm{kg}^{-1}$ as calculated by the Dulong formula. Microalgae, such as Euglena sp., are greatly suitable to the HTL process because the whole feedstock could be entirely converted, and different biochemical components could exhibit different transformation processes under HTL.

The conversion ratio of the Euglena sp. feedstock and the biooil yield with/without catalysts from HTL at $280{ }^{\circ} \mathrm{C}$ for $30 \mathrm{~min}$ are displayed in Fig. 2. All the conversion ratios rose when the catalysts of HZSM-22, HZSM-5, H beta, MCM-22, and SAPO-11 were introduced to the HTL process. The ratios were $83.82 \%$, $79.1 \%, 85.89 \%, 79.62 \%$, and $80.81 \%$, respectively, relative to the blank, which attained a conversion ratio of $78.39 \%$. This finding indicates that the catalysts introduced were slightly beneficial in enhancing the conversion ratio of Euglena sp. Meanwhile, the conversion ratios were in the order $\mathrm{H}$ beta $>$ HZSM-22 $>$ SAPO-11 $>$ MCM-22 > HZSM-5, which generally conformed to the order of decreasing amount of acidity sites listed in Table 2 . Hence, the acid sites in the catalysts helped convert the biomass. By contrast, the bio-oil yields presented an opposite tendency when catalysts were added, that is, $23.54 \%, 22.45 \%, 25.41 \%$,

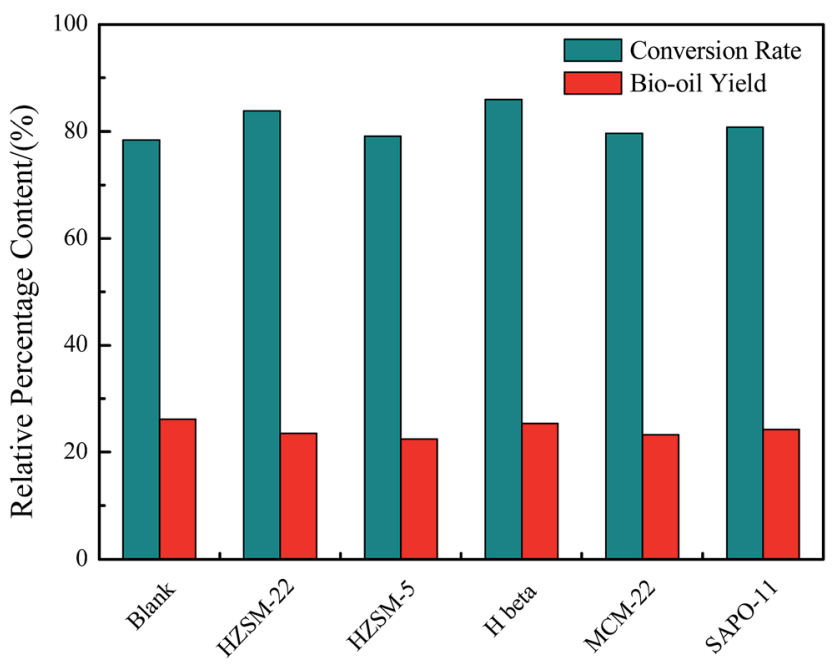

Fig. 2 The conversion ratio and the bio-oil yield over the HTL of Euglena with/without catalysts.
$23.23 \%$, and $24.3 \%$ for HZSM-22, HZSM-5, H beta, MCM-22, and SAPO-11, respectively, and $26.13 \%$ for the blank. This result might be explained by the different acidic properties of the catalysts. The different acidic properties may have promoted the occurrence of cracking reaction during conversion and slightly decreased the bio-oil yield. Although the bio-oil yield in the presence of catalysts was reduced in different degrees, the obtained constituent for each bio-oil showed obvious beneficial changes. The following points discuss the detailed analysis achieved by EA and GC-MS. As already reported, the reduced bio-oil yield could be compensated by the higher bio-oil quality (e.g., lower nitrogen and oxygen contents; higher HHV). ${ }^{19}$ The total acidity and acid strength distribution of the catalysts have been listed, and all the catalysts possessed both weak and strong acid sites (Table 2). Usually, the weak acid sites were assigned as silanol groups at the external surface or at lattice defects, and $\mathrm{OH}$ groups bonded to the extra-framework aluminum species. Meanwhile, the strong acid sites generally resulted from the framework tetrahedral aluminum species. ${ }^{15,20}$ The $\mathrm{H}$ beta catalyst exhibited the highest total acidity sites and the strongest acid sites, which were 0.19 and 0.35 , respectively. Meanwhile, during conversion, the $\mathrm{H}$ beta catalyst also showed the highest conversion ratio relative to those of the other catalyst and a lower bio-oil yield with respect to that of the blank. In addition, the large surface area $\left(582 \mathrm{~m}^{2} \mathrm{~g}^{-1}\right)$ of the $\mathrm{H}$ beta catalyst facilitated the reaction of additional organic molecules.

Table 3 displays the elemental composition, HHV, and the corresponding energy recovery ratio (ERR) of the obtained biooils. These parameters are of great importance to study of biooil quality. The contents of $\mathrm{C}(73.59 \%)$ and $\mathrm{H}(7.90 \%)$ of the blank bio-oil were much higher than those of Euglena sp. Meanwhile, the content of O (12.77\%) significantly declined with respect to that of Euglena sp. (28.87\%). This result illustrates that a higher energy density of bio-oil could be obtained from Euglena sp. feedstock by HTL treatment. By contrast, the N content of bio-oil $(5.74 \%)$ showed an increasing trend compared with that of Euglena sp. (3.81\%). This result was attained because more $\mathrm{N}$ entered the oil phase than those that entered the aqueous and gas phases through the interactions between amino acid (protein hydrolysate) and other hydrolysis products from lipid and carbohydrate. Concurrently, the HHV (33.99 $\mathrm{MJ} \mathrm{kg}^{-1}$ ) and ERR (66.83\%) rose relative to those of Euglena sp. The finding suggests that the majority of the energy content of Euglena sp. entered the bio-oil. With catalyst introduction, the contents of $\mathrm{C}$ and $\mathrm{H}$ increased distinctly, whereas the contents of $\mathrm{O}$ and $\mathrm{N}$ declined. The HHV further rose, and the order of HHV of the obtained bio-oils was consistent with that of the amount of acidity sites of the corresponding catalysts and the conversion ratios. This consistency implies that the catalytic conversion helped improve the bio-oil quality. Despite the nonprominence of $\mathrm{O}$ content variation with catalyst addition (except $\mathrm{H}$ beta, $\mathrm{O}$ content lowered $c a$. 20\%) compared with that of the blank, the types of oxygen-containing compounds changed obviously. Desirable components with good flammability and suitability for fuels, such as hydrocarbons and esters, increased significantly. Meanwhile, undesirable components, such as carboxylic acid and N-containing compounds, 
Table 2 The physicochemical characteristics of catalysts

\begin{tabular}{lllll}
\hline Catalyst & $\begin{array}{l}\text { Surface } \\
\text { area } / \mathrm{m}^{2} \mathrm{~g}^{-1}\end{array}$ & $\begin{array}{l}\text { Weak acid } \\
\text { sites/unit }\end{array}$ & $\begin{array}{l}\text { Strong acid } \\
\text { sites/unit }\end{array}$ & $\begin{array}{l}\text { Total } \\
\text { acid/unit }\end{array}$ \\
\hline HZSM-22 & 150 & 0.12 & 0.16 & 0.29 \\
HZSM-5 & 354 & 0.13 & 0.12 & 0.25 \\
H Beta & 582 & 0.15 & 0.19 & 0.35 \\
MCM-22 & 347 & 0.07 & 0.14 & 0.22 \\
SAPO-11 & 262 & 0.09 & 0.17 & 0.27 \\
\hline
\end{tabular}

decreased remarkably. Among these catalysts, $\mathrm{H}$ beta showed the optimum catalytic activity as the bio-oil contained the most contents of $\mathrm{C}(76.09 \%)$ and $\mathrm{H}(9.14 \%)$ and the lowest content of $\mathrm{O}(10.21 \%)$ and $\mathrm{N}(4.56 \%)$ relative to others. Besides, the bio-oil obtained when $\mathrm{H}$ beta was used as catalyst also attained a maximum HHV of $37.08 \mathrm{MJ} \mathrm{kg}^{-1}$. This value approached that of petroleum (43 $\left.\mathrm{MJ} \mathrm{kg}^{-1}\right){ }^{21}$ The above-mentioned results imply that the $\mathrm{H}$ beta catalyst played a favorable role in improving the bio-oil quality in deoxygenation and denitrification.

To determine the boiling-point distribution of the obtained bio-oil from Euglena sp., a simulated method of distillation was carried out by TGA.,11,22 The boiling points of the major components of the obtained bio-oils lay within the temperature range of $180{ }^{\circ} \mathrm{C}$ to $410{ }^{\circ} \mathrm{C}$ (Fig. 3), similar to the boiling point range of the gas oil components. Meanwhile, the other components that correspond to naphtha oil and heavy oil in the boiling range were relatively less in amount. Moreover, the presence of HZSM-22, $\mathrm{H}$ beta, and SAPO-11 catalysts distinctly altered the boiling-point distribution of the bio-oils. In particular, the contents of the gas oil components were further enhanced, whereas the other contents decreased. Especially, when the $\mathrm{H}$ beta was used as catalyst, the content of gas oil components reached $80.53 \%$, simultaneously, and the heavy oil content decreased to $5.27 \%$. This aspect indicated that $\mathrm{H}$ beta with high acid amount, as well as large surface area, could promote the cracking of additional macromolecules in the heavy oil components.

The GC-MS was used in this paper to identify the main components of the obtained bio-oil. Notably, the present percentage area values in this paper only illustrate the relative content of each organics in the bio-oil vaporized and passed through the GC column. The constituents of the bio-oils from Euglena sp. HTL with/without catalyst were analyzed, and the major compositions are listed in Table S1 (ESI $\dagger$ ). To study the differences of each bio-oil, the components were categorized into N-containing compounds, phenols, ketones, hydrocarbons, alcohols, esters, and acids on the basis of the functional groups (Fig. 4). The bio-oil constituents obtained from direct HTL were N-containing compounds (30.87\%), phenols $(3.55 \%)$, ketones $(15.28 \%)$, hydrocarbons $(26.25 \%)$, alcohols $(7.61 \%)$, and acids (16.44\%), respectively. We conclude that the introduction of these five catalysts changed the components of the bio-oil to some extent (ESI Table S1†). The N-containing compounds, which reduced obviously compared with that of the bio-oil obtained in the blank, indicate that the catalysts with different acidities positively affected the denitrification of the HTL process. N-Containing compounds of pyrroles and pyridine were partly eliminated, and indole and their derivatives were removed completely. Meanwhile, L-proline-derived compound was also fully converted over the added catalysts. The catalysts added likely inhibited the Maillard reaction between the amino acids and reduced sugars or the selfcondensation reaction of the amino acids to some degree.

After the catalysts were added, the contents of acids, including tridecanoic acid, tetradecanoic acid, and hexadecanoic acid, showed a downward trend. However, the content of hydrocarbons, especially 1-tetradecene, presented a remarkable rising trend. These results were attributed to the inter-reaction of the two molecules of hexadecanoic acid. The possible reaction paths are described in Fig. 5. First, condensation reaction occurs between the two molecules of hexadecanoic acid derived from the hydrolysis of lipids. A molecule each of $\mathrm{H}_{2} \mathrm{O}$ and $\mathrm{CO}_{2}$ is removed in the acidic condition. Then, symmetrical ketone intermediates are formed. Finally, the intermediates become the terminal olefins and enol through the $\gamma-\mathrm{H}$ transfer reaction. Given its instability, the enol molecule is easily converted into methyl ketones. Then, a $\gamma-\mathrm{H}$ transfer reaction transpires to generate other terminal olefins and acetone. ${ }^{23,24}$

Table 3 The physicochemical properties and energy recovery ratio of the bio-oil obtained from Euglena HTL with/without catalysts ${ }^{a}$

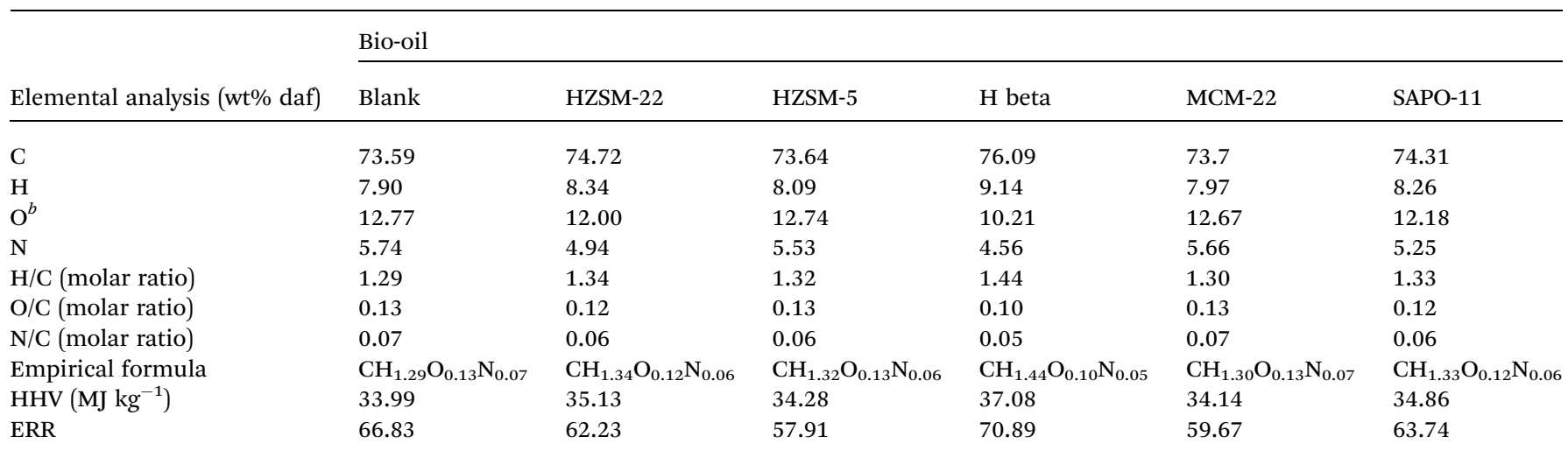

${ }^{a}$ daf $=$ dry ash free. ${ }^{b}$ Determined by difference. 


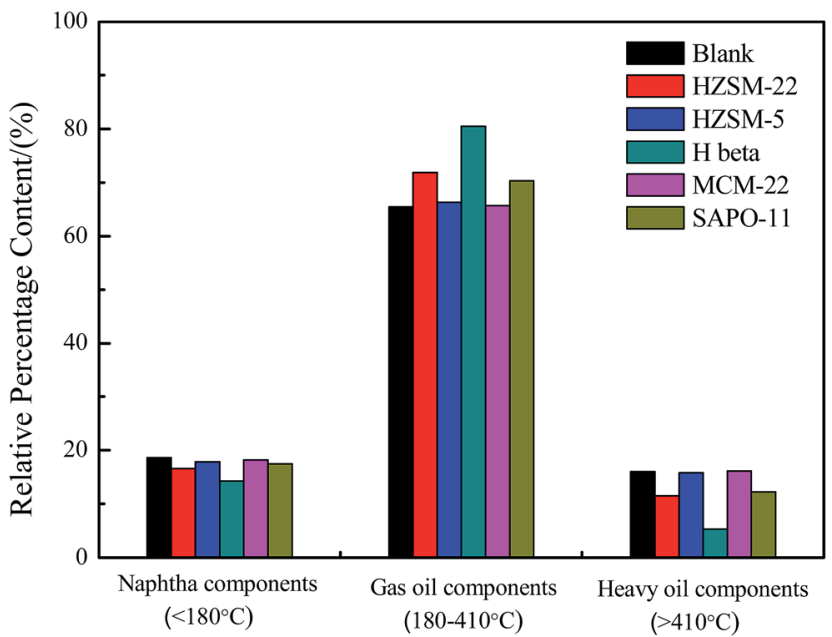

Fig. 3 The simulated distillation by TGA for the obtained bio-oil.

During direct HTL, the existence of 1-tetradecene resulted from the increased ion product that led to the increased natural levels of hydronium ions in hot-compressed water at $280{ }^{\circ} \mathrm{C}$. These conditions could result in acid-catalyzed reactions. ${ }^{5}$ The introduction of catalysts with different acidities would further accelerate the rates of the acid-catalyzed reactions and cause the 1-tetradecene content to rise again. Additionally, the alcohol content of the bio-oils with different catalysts increased slightly relative to that of the blank. The ketone content also slightly rose except in those with MCM-22 and SAPO-11. Phenols presented in the bio-oils of the blank sample and with HZSM-22 and HZSM-5 catalysts only. A certain amount of esters emerged under the effects of $\mathrm{H}$ beta and SAPO-11. By contrast, among the five catalysts, $\mathrm{H}$ beta exhibited excellent catalytic properties. The obtained bio-oil consisted of $43.43 \%$ hydrocarbons, $10.71 \%$ alcohols, $15.49 \%$ ketones, $4.20 \%$ esters, $16.68 \%$ $\mathrm{N}$-containing compounds, and $9.50 \%$ acids. Furthermore, the hexadecanoic acid was absolutely converted in the presence of $\mathrm{H}$ beta. These findings show that the $\mathrm{H}$ beta catalyst not only exerts a strong denitrification effect but also holds an outstanding conversion ability for acids. Meanwhile, the existing 1-tetradecanol may be attributed to the hydration reaction of a portion of the 1-tetradecene with water over $\mathrm{H}$ beta in the HTL process. ${ }^{25,26}$ Our purpose is to confirm which zeolite would be effective specifically for Euglena sp. HTL. Hence, we did not consider the problems of catalyst recyclability. Future work should focus on the recycle and reuse of catalysts after application in industrialized microalgal HTL.

\subsection{Reaction mechanism of the main hydrocarbon component}

Currently, many studies investigate the reaction mechanism of HTL using different microalgae as feedstock. ${ }^{27-29}$ The reaction mechanism for specific microalgae may help in the control of the properties of the obtained bio-oils. This information may guide the modulation of the process conditions for HTL and the use different catalyst types. However, clarifying each reaction

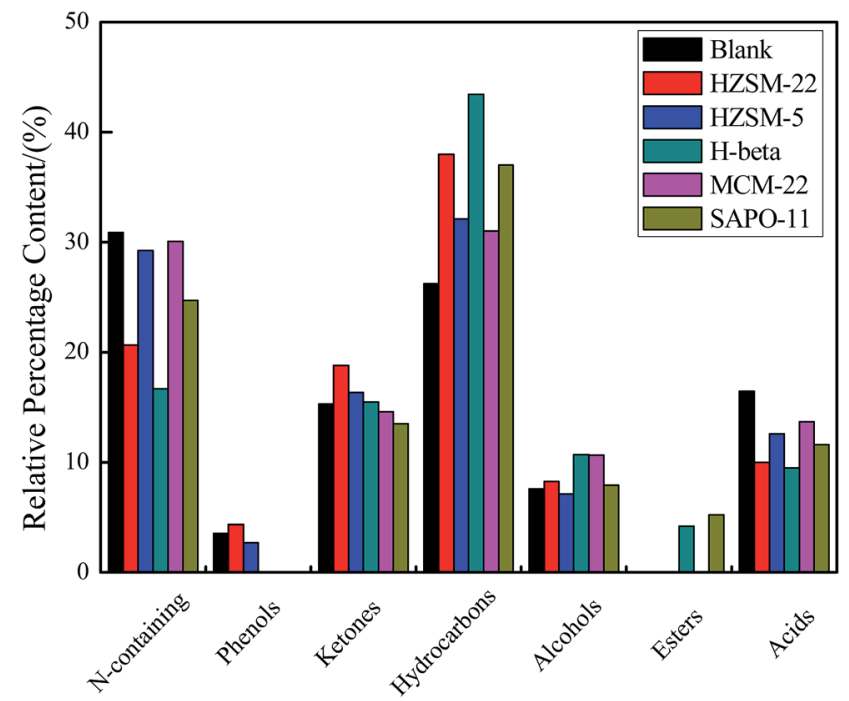

Fig. 4 The major component content from the bio-oil obtained from Euglena HTL with/without catalysts.

step is highly difficult because of the complexity of the bio-oil composition and the limited vaporization temperature of GCMS. The components of bio-oils could not be completely detected, especially the high-boiling-point compounds. ${ }^{4}$ Hence, only a portion of the compounds confirmed by GC-MS may be representative to reasonably speculate the overall possible reaction paths.

The general reaction network for the HTL of Euglena sp. was plausibly speculated mainly on the basis of GC-MS experimental results as well as previous published studies (Fig. 6). In the initial stage, the bio-macromolecules, such as carbohydrates, lipids, and proteins, were hydrolyzed with water and generated their corresponding monomer products and small molecular compounds, including monosaccharides, aliphatic acids, and amino acids. ${ }^{19,30,31}$ With increasing temperature, part of the monosaccharides produced furfural, furfural derivatives, or ketones through dehydration and isomerization. Such furfurals and furfural derivatives were determined by GC-MS in the bio-oils obtained by HTL at low temperatures $\left(<200{ }^{\circ} \mathrm{C}\right)$. Meanwhile, the aliphatic acids generated from the lipid hydrolysis could produce hydrocarbons and alcohols through a series of reactions, including condensation, decomposition, and deoxygenation. For the amino acids, deamination and decarboxylation were concurrent, and the corresponding products were $\mathrm{NH}_{3}$, aliphatic acids and $\mathrm{CO}_{2}$, and amines. A part of $\mathrm{NH}_{3}$ further reacted with the aliphatic acids derived from lipids to form amides. The rest of $\mathrm{NH}_{3}$, as well as $\mathrm{CO}_{2}$, entered into the gas phase. Meanwhile, the resultant amino acids also underwent intermolecular condensation, followed by dehydration and isomerization, to generate $\mathrm{N}$-heterocycles. In the reaction system, the esters were mainly formed by two reaction pathways. In the first pathway, aliphatic acids were derived from the hydrolysis of lipids esterified with the alcohols obtained from aliphatic acid hydrolysis. In the second pathway, the alcohols were produced from the conversion of aliphatic acids obtained from the hydrolysis of lipids esterified with the aliphatic acids 


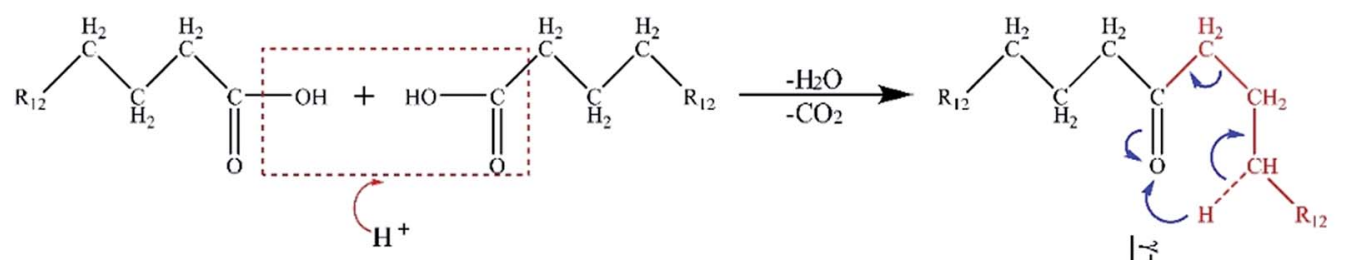

Fig. 5 The reaction path of hexadecanoic acid conversion.

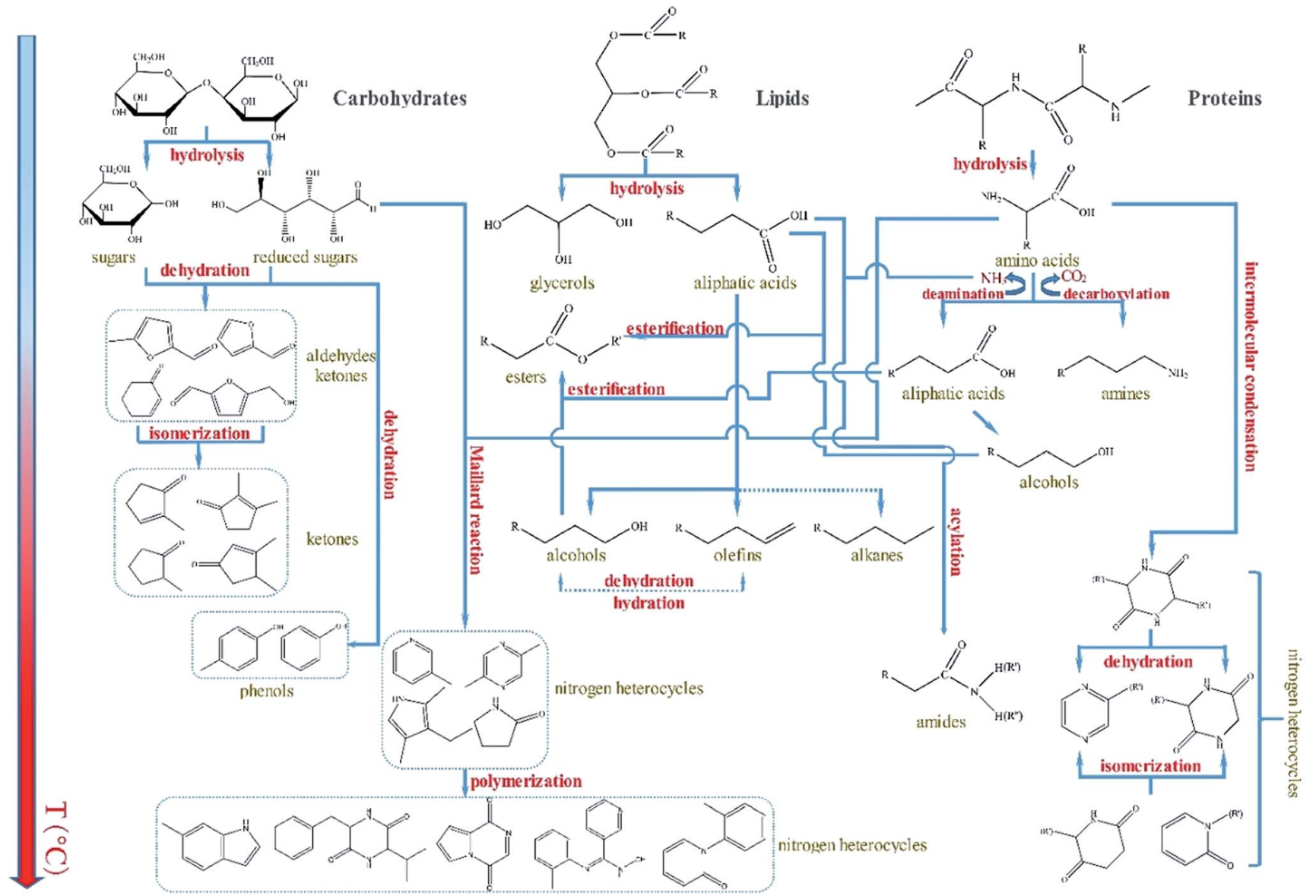

Fig. 6 The general reaction network of the HTL of Euglena. 
derived from deamination during protein hydrolysis. Another important and complicated reaction, named as Maillard reaction, ${ }^{32,33}$ occurred between reduced sugars and amino acids. The reaction chiefly generated $\mathrm{N}$-heterocycles, such as pyridine, pyrazine, pyrrole, indole, pyridinone, pyrrolidinone, and their derivatives. As mentioned above, the catalysts added not only modified the progress of the reactions and the distribution of the bio-oil products but also eventually improved the quality of the obtained bio-oil in the entire HTL process of Euglena sp.

\section{Conclusions}

Euglena sp. microalgae were first converted to bio-oil with a relatively high HHV (33.99 $\mathrm{MJ} \mathrm{kg}^{-1}$ ) via HTL without catalysts at $280{ }^{\circ} \mathrm{C}$ for $30 \mathrm{~min}$. The results illustrated that Euglena sp. is a suitable feedstock for bio-oil production. Five zeolite catalysts with different acidities were also introduced to improve the biooil quality. Among these catalysts, $\mathrm{H}$ beta exhibited the best catalytic performance. Specifically, the contents of N-containing compounds and carboxylic acids were reduced significantly to $16.68 \%$ and $9.50 \%$, respectively, and the content of hydrocarbons remarkably increased to $43.43 \%$. The formation mechanism of the main hydrocarbon component 1-tetradecene was proposed, and a general reaction network for Euglena sp. HTL was plausibly speculated.

\section{Acknowledgements}

This work was supported by the National Natural Science Foundation of China (No. 21576155, 21376140 and 21376136), the Research Project of Guangdong Provincial Department of Science and Technology Department (No. 2015B020215004), the Program for Changjiang Scholars and the Innovative Research Team in University (IRT13026) and Program for New Century Excellent Talents in University (No. NCET-12-0308).

\section{References}

1 IPCC, Climate Change 2013: The Physical Science Basis, Cambridge University Press, Cambridge, 2013.

2 P. Biller, C. Friedman and A. B. Ross, Bioresour. Technol., 2013, 136, 188-195.

3 Y. Chen, Y. L. Wu, D. R. Hua, C. Li, M. P. Harold, J. L. Wang and M. D. Yang, RSC Adv., 2015, 5, 18673-18701.

4 D. L. Barreiro, B. R. Gomez, F. Ronsse, U. Hornung, A. Kruse and W. Prins, Fuel Process. Technol., 2016, 148, 117-127.

5 T. M. Yeh, J. G. Dickinson, A. Franck, S. Linic, L. T. Thompson and P. E. Savage, J. Chem. Technol. Biotechnol., 2013, 88, 13-24.

6 A. B. Ross, P. Biller, M. L. Kubacki, H. Li, A. Lea-Langton and J. M. Jones, Fuel, 2010, 89, 2234-2243.

7 D. Zhou, L. A. Zhang, S. C. Zhang, H. B. Fu and J. M. Chen, Energy Fuels, 2010, 24, 4054-4061.

8 P. G. Duan and P. E. Savage, Ind. Eng. Chem. Res., 2011, 50, 52-61.
9 U. Jena, K. C. Das and J. R. Kastner, Appl. Energy, 2012, 98, 368-375.

10 P. Biller, R. Riley and A. B. Ross, Bioresour. Technol., 2011, 102, 4841-4848.

11 Y. Chen, Y. L. Wu, R. R. Ding, P. Zhang, J. Liu, M. D. Yang and P. Zhang, AIChE J., 2015, 61, 1118-1128.

12 Y. F. Xu, X. J. Zheng, H. Q. Yu and X. G. Hu, Bioresour. Technol., 2014, 156, 1-5.

13 G. W. Huber, S. Iborra and A. Corma, Chem. Rev., 2006, 106, 4044-4098.

14 W. B. Widayatno, G. Q. Guan, J. Rizkiana, X. Du, X. G. Hao, Z. L. Zhang and A. Abudula, Bioresour. Technol., 2015, 179, 518-523.

15 P. Duan, Y. Xu, F. Wang, B. Wang and W. Yan, Biochem. Eng. J., 2015, 116, 105-112.

16 H. J. Huang, X. Z. Yuan, G. M. Zeng, J. Y. Wang, H. Li, C. F. Zhou, X. K. Pei, Q. A. You and L. A. Chen, Fuel Process. Technol., 2011, 92, 147-153.

17 T. Minowa, T. Kondo and S. T. Sudirjo, Biomass Bioenergy, 1998, 14, 517-524.

18 S. Yokoyama, A. Suzuki, M. Murakami, T. Ogi, K. Koguchi and E. Nakamura, Fuel, 1987, 66, 1150-1155.

19 J. X. Zhang, W. T. Chen, P. Zhang, Z. Y. Luo and Y. H. Zhang, Bioresour. Technol., 2013, 133, 389-397.

20 Q. Wang, Z. M. Cui, C. Y. Cao and W. G. Song, J. Phys. Chem. C, 2011, 115, 24987-24992.

21 T. M. Brown, P. G. Duan and P. E. Savage, Energy Fuels, 2010, 24, 3639-3646.

22 C. Jazrawi, P. Biller, Y. Y. He, A. Montoya, A. B. Ross, T. Maschmeyer and B. S. Haynes, Algal Res., 2015, 8, 15-22.

23 A. Leung, D. G. B. Boocock and S. K. Konar, Energy Fuels, 1995, 9, 913-920.

24 E. Vonghia, D. G. B. Boocock, S. K. Konar and A. Leung, Energy Fuels, 1995, 9, 1090-1096.

25 K. Eguchi, T. Tokiai and H. Arai, Appl. Catal., 1987, 34, 275287.

26 H. Wang, T. Huang, J. Du and Z. M. Liu, Chin. J. Catal., 2005, 26, 451-452.

27 C. Gai, Y. H. Zhang, W. T. Chen, P. Zhang and Y. P. Dong, Energy Convers. Manage., 2015, 96, 330-339.

28 D. L. Barreiro, M. Beck, U. Hornung, F. Ronsse, A. Kruse and W. Prins, Algal Res., 2015, 11, 234-241.

29 W. Costanzo, R. Hilten, U. Jena, K. C. Das and J. R. Kastner, Algal Res., 2016, 13, 53-68.

30 S. S. Toor, L. Rosendahl and A. Rudolf, Energy, 2011, 36, 2328-2342.

31 S. D. Yin, R. Dolan, M. Harris and Z. C. Tan, Bioresour. Technol., 2010, 101, 3657-3664.

32 C. Torri, L. G. Alba, C. Samori, D. Fabbri and D. W. F. Brilman, Energy Fuels, 2012, 26, 658-671.

33 L. G. Alba, C. Torri, C. Samori, J. van der Spek, D. Fabbri, S. R. A. Kersten and D. W. F. Brilman, Energy Fuels, 2012, 26, 642-657. 